\title{
SELECTION OF LUBRICANT USING COMBINED MULTIPLE ATTRIBUTE DECISION-MAKING METHOD
}

\author{
Abhang, L. B.* \& Hameedullah, M.* \\ *Mechanical engineering Department, Aligarh Muslim University, Aligarh, India \\ E-mail: abhanglb@yahoo.co.in
}

\begin{abstract}
:
The main objective of this paper is to select a right lubricant from amongst a number of lubricants during the machining of En-31 steel work piece with tungsten carbide inserts by using combined multiple attribute decision-making method. The procedure is based on a combined TOPSIS and AHP method. The selection of an optimal material for an engineering design from a list of available alternative materials on the basis of two or more attributes in multiple attribute decision making problem. The analytic hierarchy process, being a simple, but powerful decision making tool, is being applied to solve different manufacturing problems. TOPSIS method is based on the concept that the chosen alternative should have the shortest Euclidean distance from the ideal solution and the farthest from the negative ideal solution. TOPSIS thus gives a solution that is not only closest to the hypothetical best, which is also the farthest from the hypothetically worst. Lubricant selection factors are identified and these are chip-tool interface temperature, cutting force, tool wear and surface roughness. Combined multi-attribute decision-making is aimed at integrating different measures into a single global lubricant index helps to select right lubricant and rank the given lubricant for a steel turning operation. The framework that is used in steel turning operation could serve as one of the tools for making a strategic decision. The effectiveness of our model is demonstrated through an actual experimental work.
\end{abstract}

Key Words: Multiple Attribute Decision-making, Analytic Hierarchy Process, TOPSIS Method, Turning, Minimum Quantity Lubricant

\section{INTRODUCTION}

Almost all machining process produces heat and friction which will potentially damage the cutting tools as well as the surface finish of the machined workpiece. To reduce the friction, transfer heat and to remove metal particles away from the cutting zone normally lubricants/cutting fluids are widely used in metal cutting industries during machining operation. Heat formation in machining involves two important processes, firstly generation of heat during the deformation of the metal by cutting tool and secondly friction during the movement of chips between the workpiece and the cutting tool. It is very important to provide proper lubricant to reduce the friction and remove the heat as rapidly as possible. A proper combination of cutting conditions is extremely important because this determines surface quality of manufactured parts. The growing demand for higher productivity, product quality and overall economy in manufacturing by machining and grinding, insists high material removal rate and high stability and long life of the cutting tools. But machining and grinding with high cutting velocity, feed rate and depth of cut is inherently associated with generation of large amount of heat and high cutting temperature. Such high cutting temperature not only reduces dimensional accuracy and tool life but also impairs the surface integrity of the product by inducing tensile residual stresses, surface and subsurface micro-cracks in addition to rapid oxidation and corrosion [1].

The cutting fluids serve many useful functions including, cooling of the cutting tool at higher speeds, lubricating at low speeds and high loads, increasing tool life, improving the surface finish, reducing the distortion due to temperature rise in the work piece, facilitating chip handling and disposal, providing a protective layer on the machined surface from 
oxidation and protecting the machine tool components from rust. But the application of conventional cutting fluids creates some environmental problems like environmental pollution, water pollution, and biological problems to operators [2]. Further, the cutting fluids also incur a major portion of the total manufacturing cost [3]. Machining with $\operatorname{MQL}[4,5]$, cryogenic cooling by liquid nitrogen [6] and solid lubricants [7-8] are some of the alternative approaches in this direction. Minimum quantity lubrication refers to the use of cutting fluids of only a minute amount typically of a flow rate of 50 to $500 \mathrm{ml} /$ hour, which is about three to four orders of magnitude lower than the amount commonly used in flood cooling condition, where, for example, up to 10 liters of fluid can be dispensed per minute. Varodarajan et al [4] used 2 $\mathrm{ml} / \mathrm{hr}$ oil in a flow high pressure air at $20 \mathrm{Mpa}$, while hard turning AISI4340 steel. This may call to be near dry turning. It was found that cutting under near dry had better performance than that in dry or wet cutting in terms of cutting forces, cutting temperature, surface roughness, tool life, cutting ratio and chip-tool contact length. Lower cutting force, lower cutting temperatures, better surface finish, shorter chip-tool contact length, larger cutting ratio and longer tool life were observed in near dry cutting compared with those in dry and wet machining. Same author used specially formulated cutting fluid for turning hardened steel with minimal fluid application in pulsed jet form, which brought forth superior cutting performance [5].

Application of solid-liquid lubrication in cutting has proved to be feasible alternative to cutting fluids, if it can be applied properly. If the friction at the machining zone can be minimized by providing effective lubrication, the heat generated can be reduced to some extent. If a suitable lubricant can be successfully applied in the machining zone, it leads to process improvement. Researchers Shaji \& Radhakrishnan [7] investigated the possibility of using graphite as a lubricating medium to reduce the heat generated in the grinding zone in surface grinding. Different process parameters like cutting forces, temperature, specific energy and surface roughness were observed and reported to be reduced when compared to those in grinding with conventional coolant. The feasibility of application of graphite as a solid lubricant in surface grinding was investigated by applying it in a suitable paste form to the working surface of the wheel. Solid lubricants like $\mathrm{MoS}_{2}, \mathrm{MoS}_{2}$ base grease, graphite based grease and silicon compound mixed with SAE-20 oil have been indicated improved surface quality at different proportions while machining aluminum and brass [9]. Latkar \& Basu [10] assessed the effect of machining on tool wear and surface roughness with graphite based grease mixed with base oil in varying proportions applied in MQL and compared the results with dry machining using response surface methodology while medium alloy steel was machined with tungsten carbide tool.

Boric acid $\left(\mathrm{H}_{3} \mathrm{BO}_{3}\right)$ is one of the most popular solid lubricant and has excellent lubrication properties without calling for expensive disposal techniques. The most important characteristics of boric acid for use as a lubricant are that it is readily available and cheap and environmentally safe. Several studies related to the lubrication properties of boric acid are carried out over the past several decades [11], [12]. These works have primarily focused on the performance of boric acid in high temperature applications. The studies indicated that boric acid is unique layered inter-crystalline structure; it makes a very promising solid lubricant material because of its relatively high load carrying capacity and low steady state friction coefficient (0.02). Another study focused on the use of boric acid as a lubricant in forming and drilling. In metal forming applications [13] it is shown that the boric acid provided very low friction between an aluminum work piece and a steel forming tool.

Abhang \& Hameedullah [14] investigated the possibility of using $10 \%$ boric acid by weight mixed with base oil SAE-40 as a minimum quantity lubricant, to reduce the heat generated in the machining zone (chip-tool interface) in metal cutting process. The existing procedure of lubricant selection for any given machining application are mainly identifying a lubricant matching with the cutting tools, work material combination and the metal cutting operation. To evaluate the performance of lubricants is determined by machining process output variables, such as tool wear, cutting forces, cutting temperature, power consumption, surface finish, material removal rate and dimensional accuracy etc. The selection procedure suggested by the researchers considered either a single machining process output variable 
or a number of machining process output variables and these output parameters are studied with respect to the lubricant properties and characteristics. Therefore, proper lubricants are evaluated by the researchers considering their performance with respect to each machining process output variables separately and then final decision regarding selection is taken, in a subjective manner, keeping in view the overall performance. It is clear that there is need to develop a scientific appropriate mathematical model for selection of proper lubricant during steel turning process.

Saaty [15] developed analytic hierarchy process (AHP) which decomposes a decision making problem into a system of hierarchies of objective, attribute or criteria and alternatives. AHP can effectively deals with tangible (objective) as well as non-tangible (subjective) attributes, especially where the subjective judgments of different individuals constitute an important part of the decision process. This was applied to solve various decision-making problems including the manufacturing and production areas. The analytic hierarch is a logical approach and is proved to be useful for mathematical modeling and analyzing various types of decision making situations in many fields of science and technology (Saaty). The analytical hierarchy process deals with the problem of choosing an alternative from a set of various alternatives which are characterized in terms of factors (response). Analytic hierarchy method is widely used in almost every field of human activity, for example traffic [16], agriculture [17], information technology [18], inventory control [19], materials selection [20], flexible manufacturing system selection [21], cutting fluid and machinability evaluation of work materials for a given machining operation[22]. According to Chen et al [23] AHP is one of the useful methodologies and plays an important role in selecting alternatives. For evaluating the numerous criteria, AHP has become one of the most widely used methods for the practical solution of multi-criteria decision making problems [24]. The AHP is one of the extensively used multi-criteria decision making methods. One of the main advantages of this method is the relative ease with which it handles multiple criteria. In addition to this, AHP is easier to understand and it can be effectively handle both qualitative and quantitative data. The use of AHP does not involve cumbersome mathematics. AHP involves the principle of decomposition, pair wise comparisons and priority vector generation and synthesis.

Hwang \& Yoon [25] developed Technique for order preference by similarity to ideal solution (TOPSIS) method. This method is based on the concept that the chosen alternative should have the shortest Euclidean distance from the ideal solution and the farthest from the negative ideal solution. TOPSIS thus gives a solution that is not only closest to the hypothetically best, that is also the farthest from the hypothetically worst. However, the methods proposed are complicated and involve more computation. The objective of lubricant selection procedure is to identify the lubricant properties and obtain the most appropriate combination of lubricant factors in conjunction with the actual requirement of the metal cutting operation. Thus, efforts need to extended to determine factors which influence lubricant selection for a given machining application, using a combined multiple attribute decision-making method (MADM), to eliminate unsuitable lubricant and selection of appropriate lubricant to strengthen the existing multiple attribute decision-making approach. Multiple attribute decision making is a simple, systematic, logical, easy, effective, efficient and convenient method, which affords industry for evaluation of work material, plant layout, selection of manufacturing process etc.

There appears to be a few applications of scientific methods or mathematical models to guide users in material and lubricant/cutting fluids selection. Rao [26] presented combined multiple attribute decision-making method in evaluation of machinability of work materials for a given machining operation. In another study also by Rao [27, 28] reported digraph and matrix method for the selection, identification and comparison of metal cutting fluids. Liao [29] presented a fuzzy multi-criteria decision making method to material selection. However, the method is complicated and requires more computation. Ashby [30] proposed multiobjective optimization in materials design and selection using utility functions.

In this paper, the combined multiple attribute decision-making method is used in the selection of best lubricant during steel turning operation with tungsten carbide cutting tools under different lubricating and cooling conditions, such as dry, wet and minimum quantity 
lubrication (MQL). The selection of right lubricant for a given machining application from amongst a large number of lubricants is clearly a decision making process, and hence in the present study, the application of analytic hierarchy process combined with TOPSIS is used for lubricant selection based on performance (response) of a lubricants. Multiple attribute decision-making refers to an approach of problem solving that addresses problems where the selection is made from a finite number of alternatives. The objective of this paper is to investigate the applicability of the analytical hierarchy process (AHP) combined with technique for order preference by similarity to the ideal solution (TOPSIS) to select the right lubricant during turning of En-31 steel with tungsten carbide inserts. Both are used concurrently for decision-making. Both TOPSIS and AHP are logical decision- making approaches and deal with the problem of choosing a solution from a set of candidate alternatives which are characterized in terms of some attributes [26]. Rao [26-28] suggested TOPSIS is more efficient in dealing with the tangible attributes and the number of alternatives to be assessed as compare to AHP. However TOPSIS method needs an efficient procedure to determine the relative importance of different attributes with respect to the objective, AHP provides such a procedure. Hence, to take the benefits of both the efficient methods, a combined MADM (TOPSIS and AHP) is developed and used for the selection of right lubricant from a list of available lubricants during steel turning operation. Lubricant selection factors are considered and these are chip-tool interface temperature (average cutting temperature), main cutting force (thrust force), tool wear and average surface roughness $(\mathrm{Ra})$. The details and effectiveness of the combined method are presented in this paper.

\section{PROCEDURES FOR (COMBINED AHP AND TOPSIS)}

Step 1:

The first step is to determine the objective and the pertinent evaluation attributes. Analytic hierarch process is based on the decomposition of the defined decision problem to the hierarchy structure. The hierarchy structure is a tree-like structure which consists of the main goal at the top of the hierarchy (the first level), followed by the criteria and sub-criteria (also sub-sub criteria) and finally by the alternatives at the bottom of the hierarchy (the last level), as shown in Figure1.

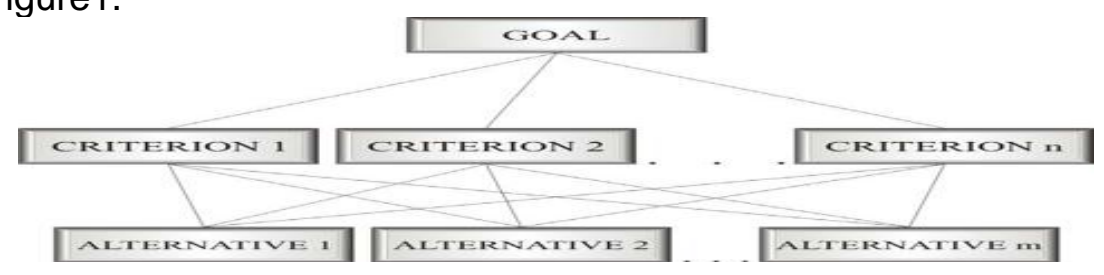

Figure 1: AHP with TOPSIS model with " $n$ " criteria and "m" alternatives.

The goal presents the optimum solution of the decision problem. It can be selection of the best alternative among many feasible alternatives. Also, the ranking of all alternatives can be performed, by obtaining the priorities. Criteria (attributes) are the quantitative or qualitative data (judgments) for evaluating the alternatives.

Step 2:

This step involves a matrix based on all the information available that describes a lubricants attributes, and is called a decision matrix. Each row of this matrix is allocated to one alternative, and each column to one attribute. Therefore, an element dij of the decision matrix $D$ gives the value of jth attribute in original real values that is a non normalized form and units for the ith alternative. Thus, if the number of alternatives is $\mathrm{M}$ and the number of attributes is $\mathrm{N}$, then the decision matrix is an MxN matrix can be represented as follows, $[D] 1_{\mathrm{MxN}}=[\mathrm{D}] 4 \times 4=[\mathrm{M}] \mathrm{ij}$

$$
[D]=\left|\begin{array}{llll}
a_{11} & a_{12} & a_{13} & a_{14} \\
a_{21} & a_{22} & a_{23} & a_{24} \\
a_{31} & a_{32} & a_{33} & a_{34} \\
a_{41} & a_{42} & a_{43} & a_{44}
\end{array}\right|
$$




\section{Step 3:}

Obtain the normalized decision matrix, Rij. This can be represented as,

$$
R_{i j}=m_{i j} /\left[\sum_{j=1}^{M} m_{i j}^{2}\right]^{1 / 2}
$$

Step 4: (a)

Determine the relative importance of different attributes with respect to the objective. To do so, one must construct pair-wise comparison matrix using a scale of relative importance. The judgments are entered using the fundamental scale of the analytic hierarchy process [15] as shown in Table1. Assuming $N$ attributes the pair-wise comparison of attribute $i$ with attribute $\mathrm{j}$ yields a square matrix $A_{N \times N}$, where, aij denotes the comparative importance of attribute $i$ with respect to attribute $j$. If the activity $i$ has one of the above non-zero numbers assigned to it when compared with activity $\mathrm{j}$, then $\mathrm{j}$ has the reciprocal value when compared with i.

Table I: Saaty's scale for pair wise comparisons.

\begin{tabular}{|c|c|c|}
\hline Scale & Definition & Explanation \\
\hline 1 & Equal importance & $\begin{array}{l}\text { Two activities contribute equally to the } \\
\text { objective }\end{array}$ \\
\hline 3 & Weak Importance & $\begin{array}{l}\text { The judgment is to favor one activity over } \\
\text { Another, but it is not conclusive }\end{array}$ \\
\hline 5 & $\begin{array}{l}\text { Essential or } \\
\text { Strong } \\
\text { Importance }\end{array}$ & $\begin{array}{l}\text { The judgment is strongly in the favor of } \\
\text { one activity over another }\end{array}$ \\
\hline 7 & $\begin{array}{l}\text { Demonstration } \\
\text { importance }\end{array}$ & $\begin{array}{l}\text { The Conclusive judgment as to the } \\
\text { Important of one activity over another }\end{array}$ \\
\hline 9 & Absolute & $\begin{array}{c}\text { The judgment in the favor of one activity } \\
\text { over another is of the highest possible } \\
\text { order of affirmation }\end{array}$ \\
\hline $2,4,6,8$ & $\begin{array}{l}\text { Intermediate } \\
\text { values } \\
\text { between the two } \\
\text { adjacent } \\
\text { judgments }\end{array}$ & When compromise is needed \\
\hline
\end{tabular}

Find the relative normalized weight $(\mathrm{Wj})$ of each factor by using the Table I provided by Saaty.

1. Calculating the geometric mean of ith row.

2. Normalizing the geometric means of rows in the comparison matrix

$$
\text { i) } \begin{aligned}
G M_{i} & =\left\{\prod_{j=1}^{N} a_{i j}\right\}^{1 / N} \\
W_{j} & =\frac{G M_{i}}{\sum_{i=1}^{N} G M_{i}}
\end{aligned}
$$

(b) Calculate matrix $A_{3}$ and $A_{4}$ such that

i) $A_{3}=A_{1} * A_{2}$

ii) $A_{4}=A 3 / A_{2}$

Where, $A_{2}=\left[W_{1}, W_{2},-------W_{N}\right]$

(c) Find out the maximum eigen values $\lambda_{\max }$ which is average of matrix $A_{4}$.

(d) Calculate the Consistency Index (Cl)

$$
C I=\left[\frac{\left(\lambda_{\max }-N\right)}{N-1}\right]
$$

(e) Obtain the Random Index (RI) for the number of factors used in decision making.

(f) Calculate the consistency ratio $(\mathrm{CR})=\mathrm{Cl} / \mathrm{RI}$

Usually a CR of 0.1 or less is considered as acceptable.

Step 5:

Obtain the weighted normalized matrix $\mathrm{V}_{\mathrm{ij} \text {. }}$ This is obtained by the multiplication of each element of the column of the matrix $R_{i j}$ with its associated weight $w_{j}$. Hence, the elements of the weighted normalized matrix $V_{i j}$ are expressed as:

$v_{i j}=w_{j} R_{i j}$ 
Step 6:

Obtain the ideal (best) and negative ideal (worst) solutions in this step. The ideal (best) and negative ideal (worst) solutions can be expressed as:

$$
\begin{aligned}
& \mathrm{V}^{+}=\left\{\left(\sum_{i}^{\max } V i j / j \in J\right),\left(\sum_{i}^{\min } V i j / j \in J^{\prime}\right) / i=1,2, \ldots . . M\right\} \\
& \mathrm{V}^{+}=\left\{V_{1}^{+}, V_{2}^{+}, V_{3}^{+}, \ldots, V_{N}^{+}\right\} \\
& \mathrm{V}^{-}=\left\{\left(\sum_{i}^{\min } V i j / j \in J\right),\left(\sum_{i}^{\max } V i j / j \in J^{\prime}\right) / i=1,2, \ldots ., M\right\} \\
& \mathrm{V}^{-}=\left\{V_{1}^{-}, V_{2}^{-}, V_{3}^{-}, \ldots, V_{N}^{-}\right\}
\end{aligned}
$$

Where $J=(j=1,2 \ldots N) / j$ are associated with beneficial attributes and $J^{\prime}=(j=1,2 \ldots N) / j$ is associated with non-beneficial attributes. $V_{j}$ indicates the ideal (best) value of the attribute for different alternatives. In case of beneficial attributes (i.e. whose higher values are desirable for the given application), $V_{j}$ indicates the higher value of the attribute. In case of nonbeneficial attributes (i.e., whose lower values are desired for the given application), $V_{j}$ indicates the lower value of the attribute. $V_{j}$ indicates the negative ideal (worst) value of the attribute for different alternatives. In case of beneficial attributes (i.e., whose higher values are desirable for the given application), $V_{j}$ indicates the lower value of the attribute. In case of non-beneficial attributes (i.e., whose lower values are desired for the given application). $V_{j}$ indicates the higher value of the attribute.

Step 7:

Obtain the separation measures. The separation of each alternative from the ideal one is given by Euclidean distance by the following equations.

$$
\begin{aligned}
& \mathrm{Si}^{+}=\left\{\sum_{j=1}^{N}\left(V_{i j}-V_{j}^{+}\right)^{2}\right\}^{0.5} i=1,2, \ldots ., N \\
& \mathrm{Si}^{-}=\left\{\sum_{j=1}^{N}\left(V_{i j}-V_{j}^{-}\right)^{2}\right\}^{0.5}, i=1,2, \ldots ., N
\end{aligned}
$$

Step 8:

The relative closeness of a particular alternative to the ideal solution, $\mathrm{P}_{\mathrm{i}}$, can be expressed in this step as follows.

$$
P_{i}=S_{i}^{-} /\left(S^{+}+S_{i}^{-}\right)
$$

Step 9:

A set of alternatives is made in the descending order in this step according to the value of $\mathrm{P}_{\mathrm{i}}$ indicating the most preferred and least preferred feasible solutions; $\mathrm{P}_{\mathrm{i}}$ may also be called as overall or composite performance score of alternative.

\section{DETAILS OF EXPERIMENTATION}

In this study, the turning operation has been conducted on En-31 steel rods with the CNMA120408 tungsten carbide inserts, cutting velocity, feed rate, depth of cut and lubricant conditions are suitably selected and given in Table II. The experiments are performed on ferrous material EN-31 steel at cutting speed, $v \mathrm{~m} / \mathrm{min}$, feed $\mathrm{f} \mathrm{mm} / \mathrm{rev}$., depth of cut $\mathrm{d} \mathrm{mm}$ and tool nose radius $r \mathrm{~mm}$ to obtain the values of chip tool interface temperatures (Tc), cutting force ( $\mathrm{Fc}$ ), tool wear rate (TW) and surface roughness ( $\mathrm{Ra}$ ) in dry, wet and minimum quantity of cutting fluid (graphite, $\mathrm{MoS}_{2}$ and boric acid powder mixed with base oil SAE-40 by weight separately) for environmentally conscious manufacturing process having particular reference to turning. The minimum quantity lubrication without formation of foam is applied to the work piece approximates $120 \mathrm{ml} / \mathrm{hr}$ that seeps into chip-tool contact area while machining En-31 steel. So the quantity is negligible this may be called as near dry machining (NDM). In this investigation, a commercial alloy steel work piece (EN31 steel alloy) is machined on heavy duty lathe machine (LTM-20). The work piece material 
used has a dimension of $500 \mathrm{~mm}$ in length and $50 \mathrm{~mm}$ in diameter. The chemical composition of the material is shown in Table3.This material is suitable for a wide variety of automotive type applications like axle, roller bearing, ball bearings, shear blades, spindle, mandrels, forming and molding dies, rollers, blanking and forming tools, knurling tools and spline shafts. There are produced using this material by turning process.

The cutting temperature is measured using tool-work thermocouple designed, fabricated and calibrated in the Mechanical Engineering lab, AMU, ALIGARH [30] as shown in Figure 2. On line measurement of cutting force is carried out using lathe tool dynamometer (strain gauge type three components lathe tool dynamometer as shown in Figure 2. Surface roughness was measured on an optical microscope (Carl-Zesis, Japan made lens factor is 0.89), the surface roughness was taken perpendicular to the turning direction. In this work an average surface roughness $(\mathrm{Ra})$ value were measured by taking average of three readings. Tool wear weight ' $W$ ' is measured on a sensitive single pan balance (maximum) 300 gram and minimum scale is 0.01 milligram). Tool inserts were properly cleaned before weighing so that dust or any other adhered particles are removed. Each experiment is repeated three times using new cutting inserts every time to obtain accurate readings of tool wear. The experimental results are shown in Table IV.

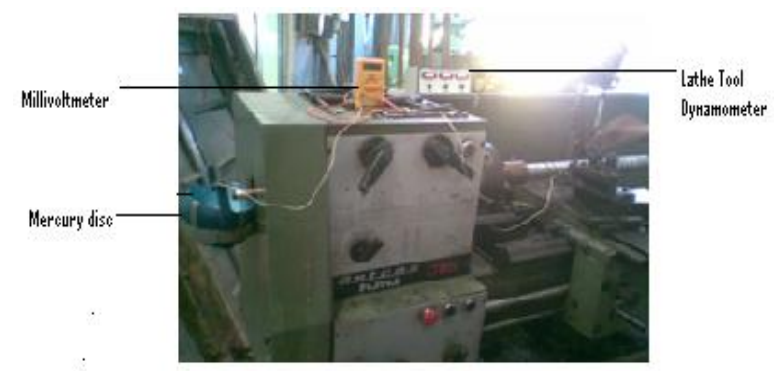

Figure2: Experimental setup for measuring average chip-tool interface temperature using Tool-work thermo-couple technique and main cutting force by lathe tool dynamometer [31].

Table II: Experimental conditions.

\begin{tabular}{|c|c|}
\hline Machine tool & 10HP lathe, LTM-20 \\
\hline $\begin{array}{l}\text { Work specimen } \\
\text { material }\end{array}$ & En-31 steel alloy \\
\hline Cutting tool holder & WIDAX SCLCR 12, Fo9 \\
\hline Configurations & CNMA 120408,diamond shape \\
\hline Process parameters & $\begin{array}{l}\text { Cutting speed, } V=112 \mathrm{~m} / \mathrm{min}, \text { Feed rate, } \\
F=0.10 \mathrm{~mm} / \mathrm{rev}, D e p t h \text { of cut, } D=0.4 \mathrm{~mm}, \text { Tool nose } \\
\text { radius, } R=0.8 \mathrm{~mm}\end{array}$ \\
\hline $\begin{array}{l}\text { Environments } \\
\text { (Lubricants) }\end{array}$ & $\begin{array}{l}\text { 1) Dry, (Absent) } \\
\text { 2) Wet (soluble oil Koolkut- } 40 \text { emulsion strength } 5- \\
10 \% \text { with water in the ratio of } 1: 20 \text { ), } \\
\text { 3) } \mathrm{MQL} \\
\text { (a) } 10 \% \text { graphite }+ \text { SAE-40 base oil, } \\
\text { (b) } 10 \% \text { MoS }+ \text { SAE } 40 \text { base oil, } \\
\text { (c) } 10 \% \text { boric acid }+ \text { SAE-40 base oil, } \\
\text { (d) } 15 \% \text { graphite }+ \text { SAE- } 40 \text { base oil, } \\
\text { (e) } 15 \% \text { MoS }+ \text { SAE- } 40 \text { base oil and } \\
\text { (f) } 15 \% \text { boric acid }+ \text { SAE-40 base oil, } \\
\text { (g) Pure SAE-40 base oil etc. }\end{array}$ \\
\hline
\end{tabular}

Table III: Chemical Composition of (EN-31) Work piece.

\begin{tabular}{|c|l|l|l|c|l|l|l|}
\hline Composition & C & Si & Mn & Cr. & Co & S & P \\
\hline Wt. \% & $0.95-$ & $0.10-$ & $0.30-$ & $1.0-$ & 0.025 & 0.04 & 0.04 \\
& 1.2 & 0.35 & 0.75 & 1 & & & \\
\hline
\end{tabular}

Table IV: Lubricants used in steel turning operation.

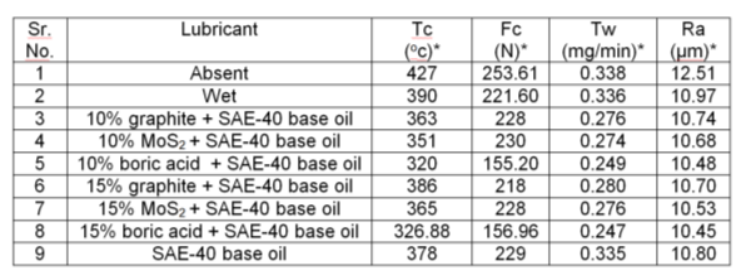

${ }^{*}$ Average of three experiment results 
The various steps of the combined methodology (AHP + TOPSIS) are carried out as shown below,

Step 1:

The objective is to select a right lubricant among a number of lubricants. The lubricant selection factors are identified. These are chip-tool interface temperature, cutting force, tool wear and surface roughness. Higher values of chip-tool interface temperature increase the surface roughness of the products, and geometric and dimensional inaccuracy of the work piece. The main cutting force affects the rating of the motor driving the work piece and higher values of cutting force means increased power consumption during steel turning process [32]. Tool wear greatly affects the chip-tool interface temperature, at cutting zone temperature is higher which makes the softening of cutting edge of the tool i.e. tool wear [33]. Generally the cutting force fluctuates about a mean value as the cutting proceeds with time, this continuous until the tool wear reaches the maximum value. Therefore, the cutting force increases rapidly due to the rapid tool wear characteristics and more friction between tool and work piece, then increase the chip-tool interface temperature during turning operation. Cutting zone temperature, tool wear, cutting forces and surface roughness are hence desired to be low. Thus, cutting zone temperature, cutting force, tool wear and surface roughness are non-beneficial factors and therefore lower values are desirable. It required deciding the significant factors to obtain degree of lubricant from cutting temperature, cutting force, tool wear and surface roughness by combined analytic hierarchy process with TOPSIS method (AHP+TOPSIS). The preferences are quantified by using a nine-point scale. The meaning of each scale measurement is explained in Table I above. The pair wise comparisons are given in terms of how much criteria A (factor-1) are more important than criteria B (factor-2). The pair wise comparison data are organized in the form of a matrix and are summarized on the basis of Saaty's eign-vector procedure, in the absolute priorities weights that will be used to calculate the overall scale of each lubricant.

Step 2:

The next step is to represent all the information available of attributes in the form of decision matrix. The data given in Table 4 is represented as matrix D1 $1_{9 \times 4}$, but not shown here.

Step 3:

The quantitative values of the lubricant attributes, given in Table IV, are normalized, as explained in section 2 (step: 3). Normalized matrix:

Step 4: (Decision matrix)

The relative importance of attributes (aij) is assigned using the AHP method, as per the procedure outlined in section 2 . Let the user makes the following assignments:

Decision matrix: $[A]_{4 \times 4}$ matrix

$[\mathrm{A}]=\mid$\begin{tabular}{llll|l}
1 & 7 & 7 & 9 & $\mathrm{Tc}$ \\
$1 / 7$ & 1 & 1 & 5 & $\mathrm{Fc}$ \\
$1 / 7$ & 1 & 1 & 3 & $\mathrm{Tw}$ \\
$1 / 9$ & $1 / 5$ & $1 / 3$ & 1 & $\mathrm{Ra}$
\end{tabular}

Now to find the relative normalized weight $(\mathrm{Wj})$ of each factor by (i) calculating the geometric mean of ith row, and (ii) normalizing the geometric means of rows in the comparison matrix.

a) $G M_{i}=\left\{\prod_{j=1}^{N} a_{i j}\right\}^{1 / N}$

b) $W_{j}=\frac{G M_{i}}{\sum_{i=1}^{N} G M_{i}}$ 


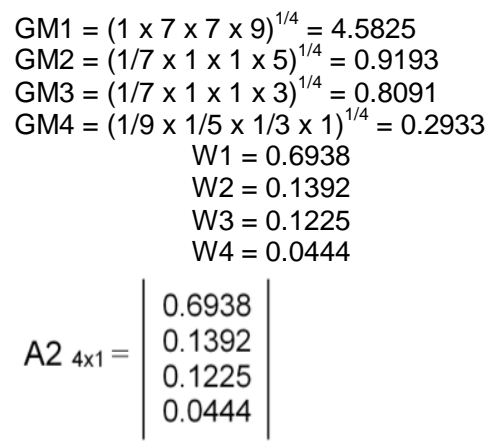

Matrix $A 3_{4 \times 1}$ is calculated as $A 3_{4 \times 1}=A 1_{4 \times 4} \times A 2_{4 \times 1}$

$$
A 3_{4 \times 1}=\left|\begin{array}{l}
2.9253 \\
0.5828 \\
0.4940 \\
0.1902
\end{array}\right|
$$

$A 3_{4 \times 1}, \lambda$ max can be worked out which is nothing but the average of matrix $A_{4 \times 1}$,

$$
\begin{gathered}
\left(\mathrm{A}_{4 \times 1}=\mathrm{A} 3_{4 \times 1} / \mathrm{A} 2_{4 \times 1}\right) \text { and can be expressed as } \\
\lambda_{\text {avg }}=\frac{1}{4} \sum_{i=1}^{N}\left(A 3_{4+1}\right)_{1} / W_{i} \\
\lambda \text { avg }=4.1799
\end{gathered}
$$

If closer the value of $\lambda$ avg to the number of attributes $n$, the result is more accurate. The deviation from accuracy is represented by consistency index $(\mathrm{Cl})$ and obtained by formula.

$$
C l=\frac{\lambda_{\text {avg }}-n}{n-1}=\frac{4.1799}{4-1}=\frac{0.1799}{3}=0.0599
$$

Random Index or correction for random error is denoted by $\mathrm{RI}$ and its value for different values of attributes $(n)$ are given by Saaty as shown in Table V.

Table V: RI Values of different values of $n$.

\begin{tabular}{|c|rcccccccr|}
\hline $\mathrm{n}$ & 1 & 2 & 3 & 4 & 5 & 6 & 7 & 8 & 9 \\
\hline $\mathrm{RI}$ & 0 & 0 & 0.58 & 0.90 & 1.12 & 1.24 & 1.32 & 1.41 & 1.45 \\
\hline
\end{tabular}

In this example $\mathrm{n}=4, \mathrm{RI}=0.90$

Consistency Ratio (CR), which is the ratio of Consistency Index to the Random Index, is calculated. This ratio $\mathrm{CR}=\mathrm{Cl} / \mathrm{RI}=0.05996 / 0.90=0.06737$ which is very less than allowed $\mathrm{CR}$ of 0.1 and hence acceptable. Thus, there is good consistency in choices of parameters made. It is thus approved that the decision matrix we took is right. We can thus proceed with solving the problem by deciding beneficial and non-beneficial attributes.

Step 5: The weighted normalized matrix $\mathrm{V} 1_{\mathrm{ij}}$ is calculated.

$$
\mathrm{V}_{\mathrm{H}_{i}}=\left|\begin{array}{cccc}
0.3233 & 00545 & 0.476 & 0.0165 \\
0.2953 & 0.0477 & 0.0472 & 0.0166 \\
0.2748 & 0.0490 & 0.0388 & 0.0141 \\
0.2657 & 0.04946 & 0.0358 & 0.0140 \\
0.2423 & 0.0334 & 0.0350 & 0.0138 \\
0.2922 & 0.0469 & 0.0394 & 0.0141 \\
0.2763 & 0.0490 & 0.0388 & 0.0139 \\
0.2469 & 0.0337 & 0.0348 & 0.0138 \\
0.2862 & 0.0492 & 0.0471 & 0.0141
\end{array}\right|
$$

Step 6:

The next step is to obtain the ideal (best) and negative ideal (worst) solutions using equation 8 and equation 9, respectively. These are given as:

$$
\begin{array}{ll}
\mathrm{V}_{\mathrm{Tc}^{+}}{ }^{+}=0.2423 & \mathrm{~V}_{\mathrm{Tc}^{-}}=0.3233 \\
\mathrm{~V}_{\mathrm{Fc}^{+}}=0.0334 & \mathrm{~V}_{\mathrm{Fc}^{-}}=0.0545 \\
\mathrm{~V}_{\mathrm{Tw}^{+}}{ }^{+}=0.0348 & \mathrm{~V}_{\mathrm{Tw}^{-}}=0.0476 \\
\mathrm{~V}_{\mathrm{Sr}^{+}}=0.0138 & \mathrm{~V}_{\mathrm{Sr}^{-}}=0.0166
\end{array}
$$

\section{Step 7:} are:

Here, the separation measures are obtained using equations 10 and equation 11 . These 


$\begin{array}{ll}\mathrm{S}_{1}{ }^{+}=0.085090 & \mathrm{~S}_{1^{-}}=0.000100 \\ \mathrm{~S}_{2}=0.056347 & \mathrm{~S}_{2^{-}}=0.028800 \\ \mathrm{~S}_{3}=0.036270 & \mathrm{~S}_{3^{-}}=0.049660 \\ \mathrm{~S}_{4^{+}}=0.028390 & \mathrm{~S}_{4^{-}}=0.059069 \\ \mathrm{~S}_{5}=0.000200 & \mathrm{~S}_{5^{-}}=0.084692 \\ \mathrm{~S}_{6}=0.051800 & \mathrm{~S}_{6}=0.0331428 \\ \mathrm{~S}_{7}=0.037620 & \mathrm{~S}_{7}=0.0482076 \\ \mathrm{~S}_{8^{+}}=0.004000 & \mathrm{~S}_{8^{-}}=0.0802570 \\ \mathrm{~S}_{9}=0.048250 & \mathrm{~S}_{9^{-}}=0.0375630\end{array}$

Step 8:

The relative closeness of a particular alternative to the ideal solution is calculated using equation12, and these are:

$\mathrm{P}_{(1)}=1.173 \times 10^{-3}, \mathrm{P}_{(2)}=0.338235, \mathrm{P}_{(3)}=0.5779156, \mathrm{P}_{(4)}=0.6753907, \mathrm{P}_{(5)}=0.997644$,

$P_{(6)}=0.3901778, P_{(7)}=0.5616794, P_{(8)}=0.9525264, P_{(9)}=0.4377308$

This relative closeness to ideal solution can be considered as the "global lubricant index (GLI)."

Step 9:

The lubricants are arranged in descending order according to their global lubricant index as shown in Table VI. This can be arranged as:

$5-8-4-3-7-9-6-2-1$.

Table VI: Rank of Lubricants (Lubricant Index).

\begin{tabular}{|l|l|l|}
\hline $\begin{array}{l}\text { Ranking } \\
\text { number }\end{array}$ & $\begin{array}{l}\text { Lubricant } \\
\text { index (LI) }\end{array}$ & Types of Lubricants \\
\hline $05(1)$ & 0.9965 & $10 \%$ boric acid in SAE-40 base oil \\
\hline $08(2)$ & 0.9560 & $15 \%$ boric acid in SAE-40 base oil \\
\hline $04(3)$ & 0.677 & $10 \%$ MoS2 in SAE-40 base oil \\
\hline $07(4)$ & 0.6041 & $15 \%$ MoS2 in SAE-40 base oil \\
\hline $03(5)$ & 0.5726 & $10 \%$ graphite in SAE-40 base oil \\
\hline $09(6)$ & 0.445 & SAE-40 base oil \\
\hline $06(7)$ & 0.4328 & $15 \%$ graphite in SAE-40 base oil \\
\hline $02(8)$ & 0.289 & Wet (conventional coolant) \\
\hline $01(9)$ & $1.243^{*} 10^{-3}$ & Absent (dry) \\
\hline
\end{tabular}

From the above calculation of lubricant index, it is clear that the $10 \%$ boric acid mixed with SAE-40 base oil by weight is the best minimum quantity lubricant (MQL) amongst all for turning En-31 steel alloy for given machining conditions. This result agrees with [14].

The next alternative is $15 \%$ boric acid in SAE-40 base oil. The lubricants $10 \%$ and $15 \%$ boric acid in SAE-40 base oil are close competitors. The $10 \%$ boric acid offers overall lowest values of chip-tool interface temperature and cutting forces. Lubricant $10 \% \mathrm{MoS}_{2}$ in SAE-40 base oil offers the next lowest values of tool wear rate and surface roughness during steel turning operation. The decrease in the tool wear rate, surface roughness, and chip-tool interface temperatures and cutting force due to good lubrication and cooling action between chip-tool interface junction while turning operation. This is due to the layered lattice structure of these solid lubricants. The lubricating action of the minimum quantity lubricants reduces the frictional forces, between chip and tool interface and tool and workpiece interface, hence reducing the temperature developed and ultimately preventing the tool wear and prolonging the tool life, which results in surface quality improvement. This improvement can be attributed to the favorable chip-tool and tool workpiece interaction and reduction of chip-tool interface temperatures while machining. So, there is decrease of chip-tool interface temperature, cutting forces, tool wear rate and surface roughness values approximately from $9 \%$ to $14 \%$ due to flooded machining. 12 to $30 \%$ due to $10 \%$ graphite + SAE-40 oil, $35 \%$ due to $10 \% \mathrm{MoS}_{2}+\mathrm{SAE}-40$ oil and $46.34 \%$ due to $10 \%$ boric acid + SAE-40 oil. Thus taking into consideration all the four lubricant factors simultaneously, $10 \%$ boric acid in SAE-40 base oil is proved to be the best minimum quantity lubricant as compared to other lubricants. The above results, determined using the combined TOPSIS-Analytical Hierarchy Process (AHP), are agreed well with the experimental results [14]. It may be noted that the above ranking of lubricants may be change if the user assigns different relative importance values to the attributes. The performances of selected lubricants are agreed well with the experimental results [14]. The proposed combined TOPSIS- AHP method offers more objective, flexible, simple, weights of relative importance, checks the consistency mode in judgments and is applicable to any type of metal cutting operations in metal machining industries on shop floor area. Further more, the combined TOPSIS-AHP method can consider any number of 
quantitative and qualitative lubricant criteria (attributes) simultaneously, and offers more objective and logical approach.

\section{CONCLUSION}

1) The applicability of the combined TOPSIS-AHP method for selection of right lubricant based on lubricant performance such as chip-tool interface temperature, main cutting force, tool wear rate and surface finish are explored in this work.

2) It is found that the $10 \%$ boric acid in SAE-40 base oil is the best choice of minimum quantity lubricant as compared to other lubricants. Thus, the combined TOPSIS-AHP method can be applied successfully to select the right choice of lubricant during steel turning operation.

3) The proposed method identifies and considers lubricant factors and their correlations for a given metal cutting operation.

4) The proposed global lubricant index evaluates and ranks best lubricant during steel turning operation. Also, the proposed method helps in selecting the best lubricant from among the number of lubricants in steel turning operation. The proposed method is applicable to any type of machining operation and can consider any number of quantitative and qualitative lubricants attributes simultaneously. Thus, it offers a more objective, logical, simple and consistent lubricant selection approach and is applicable to any type of metal cutting operations in industries on shop floor area.

5) Combined TOPSIS-AHP method is a managerial decision making mathematical modeling technique that will be helpful to researchers and managers in the selection of right lubricant in metal cutting industries. Hence technique for order preference by similarity to ideal solution (TOPSIS) with analytic hierarchy process (AHP) method provides a convenient approach for solving complex multi-criteria decision making problems in manufacturing domains.

\section{ACKNOWLEDGEMENTS}

The authors would like to express their deep gratitude to the Department of Mechanical Engineering of Aligarh Muslim University (AMU) for providing the laboratory facilities and financial support.

\section{REFERENCES}

[1] Leskover, p; Grum, J. (1986). The metallurgical aspect of machining, Annals of CIRP 35/1, 537-550

[2] Byrne, G; Scholta, E. (1993). Environmental clean machining processes a strategic approach, Annals of the CIRP, Vol.42, 471- 474

[3] Klocke, F; Eisenblatter, G. (1997). Dry cutting, Annals of the CIRP, Vol. 46, 520-526

[4] Varadarajan, A. S; Philip, P. K; Ramamoorthy, B. (2002). Investigations on hard turning with minimal cutting fluid application (HTMF) and itscomparison with dry and wet turning, International Journal of Machine Tools and Manufacture, 42 (2), 193-200

[5] Varadarajan, A. S; Ramamurty, B; Philip, P. K. (2003). Formulation of a cutting fluid for hard turning with minimal cutting fluid, Proceddings of 20th, AIMTDR, Birla Institute of Technology Mesra, Ranchi,.89-96

[6] Pauls, S; Chattopadhay, V. (1995). Effect of cryogenic cooling by liquid nitrogen jet on forces, temperature and surface residual stresses in grinding steels, Cryogenics, Vol.35 (8), 515-523.

[7] Shaji, S; Radhakrishnan, V. (2002). An investigation on surface grinding using graphite as lubricant, International Journal of Machine Tools and Manufacture, Vol. 42 (6),733-740

[8] Reddy, N. S. K; Rao, P. V. (2006). Performance improvement of end milling using graphite as a solid lubricant, Materials and Manufacturing Processes, Vol. 20, pp.1-14

[9] Deshmukh, S. D; Basu, S. K. (2006), Significance of solid lubricants in metal cutting, Proceedings of 22nd All India Manufacturing Technology, Design and Research, (AIMTDR), Chennai,pp.156- 162 
[10] Lathkar, G., S; Kharde, R. R; Basu, S. K. (2001). Some experiments in machining grease based solid lubricants, Journal of the Institution of Engineers, (India), vol. 82, 01- 06

[11] Edemir, A. (1991). Tribological properties of boric acid and boric acid forming surfaces, Part I. Crystal Chemistry and Mechanism of self lubrication of boric acid, Lubrication Engineering. Vol. 47, 168-178

[12] Erdemir, A. (2008). Synergistic effects of liquid and boric acid solid lubricant films on friction and wear of sliding steel surfaces, Tribology section, Materials and Components Technology Division, Argonne National lab In: /www.lubron.com/pdf/synergistic effects, 238-249.

[13] Liang, H; Jahangir, S. (1995). Boric acid as additive for core drilling of Alumina, Journal of Tribology, Vol. 117, 65-71

[14] Abhang, L .B; Hameedullah, M. (2010). Control of chip-tool interface temperature for improved productivity through a new lubricating technique, International Journal of Applied Engineering Research, vol.5, No.14, 2373-2382

[15] Saaty T.L., How to make a decision, the analytic hierarchy process, European Journal of operation research, 48,1,9-26,1990

[16] Pogarcic, I; Francic, M; Davidovic,V. (2008). Application of AHP method in traffic planning ISEP, Proceedings of ITS-A Condition for Sustainable Development and Prosperity of A Modern and Safe transport/ ed.Hernavs, pavel, 230-239

[17] Rozman, C. (2005). Application of computer supported multi-criteria decision models in agricultre. Agricultre Conspectus Scientificus, 70, 4, 127-134

[18] Braglia, M; Carmignani, G; Frosolini, M; Grassi, A. (2006). Ahp based evaluation of CMMS software. Journal of Manufacturing Technology Management, 17, 5, 585-602

[19] Simunovic, K; Draganiac, T. (2008). Application of different quantitative techniques to inventory classification. Technical Gazette,15, 4, 41-47

[20] Venkata, Rao. (2008). A decision making methodology for material selection using an improved compromise ranking method, Materials and Design, 29, 1949-1954

[21] Dr. Mohammed Ali, Mukesh Kumar. ( 2008). An analytic hierarchy process (AHP) framework for selecting flexible manufacturing system, Journal of Management Dynamics, Lucknow, vol.8-1, 56-70

[22] Venkata Rao. (2006). Machiniability evaluation of work materials using a combined multiple attribute decision- making method, International Journal of Advanced Manufacturing Technology, 28; 221-227

[23] Chan, F. T. S; Chan, M. S; Tang, N. K. H. (2000). Evaluation methodologies for Technology selection, Journal of Materials Processing Technology, Vol.107, 330-337

[24] Liu, D; Duan, G; .Lei, N; Wang, J. S. (1999). AHP based decision modeling in CAPP Development Tools, International Journal of Advanced Manufacturing Technology, Vol.15-2631

[25] Hwang, C.L; Yoon, K. (1981). Multiple Attribute decision making-methods and Application, Springer Verlag, New York

[26] Venkata Rao. (2006). Machinability evaluation of work materials using a combined multiple attribute decision-making method, International Journal of Advanced Manufacturing Technology, 28: 221-227

[27] Venketa Rao; Gandhi, O. P. (2001). Diagraph and matrix method for the selection, identification and comparison of metal cutting fluids, Proceedings of the Institution of Mechanical Engineering, vol.216, no.1, 24

[28] Dr. Rao,V. (2010). Seminar notes on ( Advanced Engineering Optimization), Organised by Department of Production Engineering, K .K. Wagh I. E. E. and R, Nashik-03,1-2 Feb.2010.

[29] Liao, T. W. (2005). A multi-criteria decision making method for material selection, Journal of Manufacturing Systems, 29: 209-215

[30] Ashby, M. F. (2000). Multi-objective optimization in material design and selection, Materials and Design, 48, 359-369

[31] Abhang, L. B; Hameedullah, M. (2010). Chip-tool interface temperature prediction model for turning process, International Journal of Engineering Science and Technology, vol.2 (4), 382393

[32] Abhang, L. B; Hameedullah, M. (2010). Power prediction model for Turning En-31 steel Using Response surface methodology, Journal of Engineering Science and Technology Review, 3 (1), 116-122

[33] Abhang, L. B; Hameedullah, M. (2011). Model for tool wear rate in metal cutting using response surface methodology, International Journal of Manufacturing Technology and Management, 2011 (Accepted for publication) 